\title{
Korespondesi Bunyi Bahasa Aceh dan Bahasa Gayo
}

\author{
Riris Tiani \\ Fakultas Ilmu Budaya, Universitas Diponegoro \\ tiani.riris@gmail.com
}

\begin{abstract}
Acehnese and Gayonese belong to Austronesian languages which are cognate genetically. Adjacent location became the basis for the assumption that both language are related one of the linguistic kinship indicators described in comparative historical linguistic studies in occurrence of sound changes that occur regularly. The two languages show similar specific features. One of them is a phenomenon of sound changes that is called a phonemic correspondence. The sound changes in the two languages happen continuously. In this paper, the writer wants to prove the cognate phenomenon by using a comparative analysis, especially by applying a phonemic correspondence technique. Based on similarities in form and correspondence phonemes technique, it was found that the formula of the phonemic correspondence in Acehnese and Gayonese are: $* a$ and $* u>$ in phonemic correspondence $/ a \sim e /, / a \sim o /, / o \sim u /$, and $/ e \sim u /$ especially on position penultima bilabial, palatal, dorsovelar, and faringal.
\end{abstract}

Keyword: phonemic correspondence, Acehnese, Gayonese.

\section{Intisari}

Bahasa Aceh dan bahasa Gayo merupakan bahasa Austronesia yang secara genetis bersifat kognat. Letak yang berdekatan menjadi dasar asumsi kedua bahasa tersebut kekerabatan. Salah satu indikator kekerabatan bahasa yang dijelaskan dalam kajian linguistic historis komparatif yakni adanya perubahan bunyi bahasa yang terjadi secara teratur. Hal ini ditunjukan oleh okurensi perubahan bunyi yang disebut korespondensi fonemis. Perubahan bunyi bahasa Aceh dan bahasa Gayo terjadi secara konstan dan teratur pada setiap segmen dari glos yang dibandingkan. Berdasar pada kesamaan bentuk dan makna, dengan menggunakan teknik korespondensi fonemis, diperoleh formula korespondensi fonemis dalam bahasa Aceh dan bahasa Gayo sebagai berikut: *a dan *u $>$ memiliki korespondensi fonemis /a $\sim$ /, /a $\sim \mathrm{o} /$, /o $\sim \mathrm{u} /$, dan /e $\sim \mathrm{u} /$ terutama pada posisi penultima bilabial, palatal, dorsovelar, dan faringal.

Kata Kunci: korespondensi fonemis, bahasa Aceh dan bahasa Gayo.

\section{Pendahuluan}

Alur pergerakan bahasa banyak dipengaruhi oleh perkembangan masyarakat penuturnya. Hal ini merupakan fakta empiris yang implikasinya belum lama disadari dalam perkembangan telaah bahasa. Perkembangan bahasa yang relatif berbeda awalnya terjadi hanya pada tataran dialek saja, sehingga dua kelompok penutur bahasa tersebut masih dapat saling dimengerti (Nababan, 1991:17). Perbedaan dialek dalam satu periode dari suatu bahasa semakin besar, hal ini dapat mengakibatkan terjadinya perbedaan ragam 
bahasa, tetapi bahasa-bahasa tersebut masih berkerabat atau mempunyai satu bahasa tua atau proto.

Perbedaan ragam bahasa yang terjadi, dapat diklasifikasikan dengan cara pengelompokkan bahasa-bahasa berdasarkan topik-topik tertentu dengan mengadakan generalisasi bagi tiap kelompok. Ciri-ciri tertentu yang dimiliki bersama oleh sejumlah bahasa, dan beberapa kelompok bahasa-bahasa tersebut dimasukkan dalam satu kelompok yang homogeny, dan beberapa kelompok dapat dimasukkan lagi dalam kelompokkelompok yabg lebih besar. Semakin besar kelompok yang dihasilkan berdasar ciri-ciri tertentu, semakin sedikit jumlah kelas kata bahasa yang ada, dan semakin sempit keanggotaan kelompok semakin banyak jumlah kelas kata bahasa yang diperoleh. Hal terpenting, bahwa bahasa-bahasa dikelompokkan dalam satu kesatuan bahasa tersebut mirip satu sama lain.

Kemiripan atau kesamaan bentuk dan makna sebagai akibat dari perkembangan sejarah yang sama atau perkembangan dari suatu bahasa proto yang sama. Bahasa-bahasa yang mempunyai hubungan yang sama atau berasal dari suatu bahasa proto yang sama, kemudian berkembang menjadi bahasa-bahasa baru, maka dimasukkan dalam satu keluarga bahasa (language family) yang berarti bentuk kerabat.

Bahasa dianggap berkerabat dengan kelompok bahasa tertentu apabila secara relative memperlihatkan kesamaan yang besar bila dibandingkan kelompok-kelompok lainnya. Perubahan fonemis dalam sejarah bahasa-bahasa tertentu memperlihatkan pula sifat yang teratur. Semakin dalam menelusuri sejarah bahasa-bahasa kerabat, maka akan semakin banyak didapat kesamaan antar pokok-pokok bahasa yang dibandingkan.

Oleh sebab itu, korespondensi yang teratur antarbahasa dapat dijelaskan sebagai akibat perubahan fonemis yang teratur antara bahasa-bahasa kerabat. Sedangkan keteraturan antarsegmen sebagai akibat dari perubahan fonemis yang teratur di mana keadaan itu muncul pada situasi yang berbeda. Kemiripan atau kesamaan bentuk dan makna terdapat dalam bahasa-bahasa di Nusantara. Bahasa-bahasa daerah di Nusantara yang termasuk dalam rumpun bahasa Austronesia memiliki banyak kesamaan yang masih dapat diusut, karena berasal dari satu induk bahasa yang sama. Kemiripan atau kesamaan bentuk dan makna juga terlihat pada bahasa Aceh dan Gayo. Keduanya termasuk dalam rumpun bahasa Austronesia, tepatnya kelompok bahasa Austronesia Barat yakni bahasabahasa Hesperonasia (bahasa-bahasa Indonesia Barat) (keraf,1990:205). Kedua bahasa 
tersebut secara geografis berada pada wilayah yang berdekatan di Pulau Sumatra tepatnya di provinsi Aceh

Linguistik Hirtoris Komparatif bagian dari ilmu linguistik struktural yang mempersoalkan bahasa dalam bidang waktu tertentu, serta mengkaji perubahan unsur bahasa yang terjadi dalam bidang waktu tertentu (Keraf, 1990:22). Tetapi tidak menutup kemungkinan kajian historis komparatif melibatkan pandangan diakronis. Karena penelitian bahasa tidak akan lepas dari perkembahangan bahasa yang pernah dipakai oleh masyarakat penuturnya.

Konsep dasar dalam Linguistik Historis Komparatif adalah perbandingan dua bahasa atau lebih dikatakan berkerabat apabila bahasa-bahasa yang dipakai tersebut berasal dari satu bahasa yang sama pada masa lampau. Hal tersebut dipengaruhi oleh gerak migrasi, faktor migrasi perubahan dan perkembangan bahasa berbanding lurus dengan penutur yang dipengaruhi bahasa induknya. Migrasi keluar dan dalam diantaranya disebabkan oleh pernikahan antaretnis, bencana alam, dan adanya penjajahan pada etnis tertentu sehinggan menyebabkan kepunahan penutur yang berakibat kepunahan bahasa. Atau karena pengaruh bahasa masyarakat pendatang lebih kuat sehingga bahasa pada masyarakat asli tidak berkembang dan tidak bisa bertahan.

Menurut Keraf (1996:36) dasar pemikiran dalam teori perbandingan meliputi kesamaan bentuk dan makna yang dipengaruhi oleh factor warisan langsung (inherintance) dari bahasa induk yang sama atau disebut cognate. Kedua, faktor kebetulan (by chance) bahwa ada kesamanan bunyi dan makna dalam bahasa yang dibandingkan tetapi secara geografis dan historis tidak memiliki hubungan langsung. Ketiga, karena faktor pinjaman (borrowing) karena mobilitas yang tinggi, maka suatu bahasa berpotensi untuk menyerap bahasa tertentu dikarenakan perkembangan jaman dan kebutuhan akan bahasa tersebut.

Penelitian sebelumnya yang ditulis oleh tiani (2010) tentang "Korespondesi Fonemis Bahasa Bali dan Bahasa Sasak" memperlihatkan keteraturan bunyi antarsegmen dalam beberapa gloss. Keteraturan tersebut tampak pada refleksi formula korespondesi fonemis bentuk vokal dalam bahasa Bali dan Sumbawa berupa $*_{a}$ >o a dan palatal dan $* \mathrm{u}>\mathrm{u} \sim \mathrm{i}$, pada posisi ultima tertutup. Keteraturan antarsegmen yang muncul secara berulang dalam bahasa Bali dan bahasa Sumbawa merupakan bukti bahwa kedua bahasa tersebut berkerabat dengan proto Austronesia.

LinguistikHistoris Komparatif menggunakan prinsip dasar kesamaan dalam bentuk dan makna sebagai pantulan sejarah warisan yang sama. Bahasa-bahasa yang berkerabat 
serasal dari bahasa induk atau proto sama dengan memperlihatkan keteraturan fonetik, fonologis, morfologis, dan sintaksis. Dalam penelitian ini, penulis akan mendeskripsikan bentuk keteraturan perubahan bunyi yang terjadi secara teratur pada bahasa Aceh dan bahasa Gayo.

\section{Metode}

Data direduksi dari kosakata dasar swadesh, yang telah teruji dalam beberapa bahasa yang retensi hilangnya selama 1000 tahun. Merujuk pada kamus bahasa daerah bahasa Aceh dan bahasa Gayo, gloss yang digunakan mewakili beberapa kategori kata, diantaranya kata ganti, bilangan, kata benda, dan kata kerja yang meliputi aktifitas sehari-hari.

Setelah data diperoleh, akan dianalisis menggunakan metode perbandingan dengan teknik korespondensi fonemis. Korespondensi fonemis bertujuan untuk menemukan hubungan antarbahasa yang dibandingkan dalam bidang bunyi bahasa. Langka kerja sebagai berikut, mengidentifikasi gloss yang diduga memiliki nilai korespondensi, bandingkan fonem demi fonem dari tiap segmen yang terdapat pada posisi yang sama, klasifikasikan dalam satu perangkat korespondensi, setelah didapat perangkat korespondensi yang muncul secara teratur dari bahasa yang dibandingkan, lalu merumuskan formula korespondensi dari bahasa yang dibandingkan.

\section{Hasil dan Pembahasan}

Dilihat dari sifat perkembangan bahasa, kedua bahasa tersebut masih hidup dan digunakan oleh masyarakat pemakai bahasa yang bersangkutan. Bahasa Aceh dan bahasa Gayo digunakan sebagai alat komunikasi intraetnis oleh masyarakat suku bangsa Aceh. Persebaran bahasa Aceh dan Gayo di provinsi Aceh mulai di pesisir ujung utara, ujung timur, barat, hingga tengah dan tenggara.

Kedua bahasa yang penulis kaji, memperlihatkan perubahan fonemis yang teratur. Perubahan tersebut dapat tampak pada bahasa proto * buta' direleksikan buta 'buta' dalam bahasa Aceh, bute 'buta' dalam bahasa Gayo. Selain menunjukkan perubahan fonemis, bahasa Aceh dan bahasa Gayo juga memiliki sifat kekerabatan karena secara geografis berdekatan. Sifat kekerabatan ini bisa dijelaskan melalui besarnya turunan langsung dari proto Austronesianya. Korespondensi fomenis yang dapat diidentifikasi pada bahasa Aceh dan bahasa Gayo sebagai berikut: 


\begin{tabular}{|c|c|c|c|c|}
\hline Gloss & $\begin{array}{c}\text { Bahasa } \\
\text { Aceh }\end{array}$ & $\begin{array}{c}\text { Bahasa } \\
\text { Gayo }\end{array}$ & PAN & $\begin{array}{l}\text { Korespondensi } \\
\text { Fonemis }\end{array}$ \\
\hline \multicolumn{5}{|c|}{$\mathbf{a} \sim \mathbf{e}$} \\
\hline biasa & Biasa & biase & *biasa & $a \sim e$ \\
\hline buaya & Buya & buye & *buhaya & $a \sim e$ \\
\hline buta & Buta & bute & *buta' & $a \sim e$ \\
\hline dada & dada & dede & $*$ dada & $a \sim e$ \\
\hline dua & dua & due & $*$ dua & $a \sim e$ \\
\hline darat & darat & deret & *daRat & $a \sim e$ \\
\hline gigit & $\mathrm{Kab}$ & ket & * gigit & $a \sim e$ \\
\hline gatal & gatai & gatel & * gatel & $a \sim e$ \\
\hline hisap & isap & isep & $*$ is $\partial p$ & $\mathrm{a} \sim \mathrm{e}$ \\
\hline hitam & itam & item & $* \mathrm{i}(\mathrm{n}) \mathrm{t} \partial \mathrm{m}$ & $a \sim e$ \\
\hline ikan & ikan & iken & *'ikan & $a \sim e$ \\
\hline ingat & inat & inet & $*_{\text {iNat }}$ & $a \sim e$ \\
\hline karena & seubab & sebeb & *kwalana & $a \sim e$ \\
\hline malam & malam & kelem & $*\left[^{6}\right] \mathrm{al} \partial \mathrm{m}$ & $a \sim e$ \\
\hline luas & luwas & lues & *luha & $a \sim e$ \\
\hline sabit, arit & sadeup & sedep & $*$ ari $(\mathrm{Ct})$ & $a \sim e$ \\
\hline tebal & teubai & tebel & *kapal & $a \sim e$ \\
\hline tajam & tajam & tejem & $*^{\prime} \operatorname{tad}^{\prime} \partial \mathrm{m}$ & $a \sim e$ \\
\hline tubuh & badan & beden & *badan & $a \sim e$ \\
\hline tongkat & tuykat & tuykep & $* \mathrm{t} \partial \mathrm{k} \partial \mathrm{n}$ & $a \sim e$ \\
\hline \multicolumn{5}{|c|}{$\mathbf{a} \sim \mathbf{0}$} \\
\hline bangau & bayau & bayo & *bayau & $a \sim 0$ \\
\hline
\end{tabular}




\begin{tabular}{|c|c|c|c|c|}
\hline ikat & ikat & ikot & *ikat & $a \sim 0$ \\
\hline muda & muda & mudo & *muda & $a \sim 0$ \\
\hline rumah & rumoh & umah & *yumah & $\overline{a \sim 0}$ \\
\hline \multicolumn{5}{|c|}{ o $\mathbf{U}$} \\
\hline apung & apôy & apun & *apuy & $\mathrm{o} \sim \mathrm{U}$ \\
\hline buluh & bulôh & uluh & *buluh & $\mathrm{o} \sim \mathrm{u}$ \\
\hline bunuh & bunoh & unuh & *bunuh & $\overline{\mathrm{O} \sim \mathrm{U}}$ \\
\hline cangkul & cankoi & cankul & *caNkul & $\overline{\mathrm{O} \sim \mathrm{U}}$ \\
\hline lembu & leumo & lemu & *lembu' & $\overline{\mathrm{O} \sim \mathrm{U}}$ \\
\hline pintu & pinto & pintu & *pIntu & $\mathrm{O} \sim \mathrm{u}$ \\
\hline putih & puteh & potih & *putih & $\mathrm{O} \sim \mathrm{u}$ \\
\hline kotor & kuto & kotor & *labu & $\overline{\mathrm{O} \sim \mathrm{U}}$ \\
\hline mabuk & mabôk & mabuk & *Inum & $\hat{\mathrm{o} \sim u}$ \\
\hline sarung & saron & saruy & $*_{\text {saruN }}$ & $\overline{\mathrm{O} \sim \mathrm{U}}$ \\
\hline takut & takot & takut & *takut & $\mathrm{O} \sim \mathrm{U}$ \\
\hline tahun & thon & Tun & *tahun & $\overline{\mathrm{O} \sim \mathrm{U}}$ \\
\hline \multicolumn{5}{|c|}{$\mathbf{e} \sim \mathbf{u}$} \\
\hline abu & abée & $\mathrm{au}$ & *abu & $\mathrm{e} \sim \mathrm{u}$ \\
\hline anjing & asée & asu & *asu & $\mathrm{e} \sim \mathrm{u}$ \\
\hline duda & balée & balu & *balu & $\mathrm{e} \sim \mathrm{u}$ \\
\hline kepala & ulee & ulu & $*$ ulu & $\bar{e} \sim \mathrm{u}$ \\
\hline kutu & kute & kutu & *kutu' & $\mathrm{e} \sim \mathrm{u}$ \\
\hline janda & balée & balu & *balu & $\bar{e} \sim \mathrm{u}$ \\
\hline ribu & ribee & ribu & *rIbu & $\overline{\mathrm{e} \sim \mathrm{u}}$ \\
\hline
\end{tabular}

Sumber: Kamus Proto Austronesia (Wurm Wilson,1978). 
Formula korespondensi fonemis /a e/, fonem proto *a dalam bahasa Aceh tetap dipertahankan fonem /a/, sedangkan fonem proto *a dalam bahasa Gayo direfleksikan menjadi fonem /e/. Korespondensi fonemis /a e/ pada bahasa Aceh dan bahasa Gayo muncul pada posisi penultima terbuka dan penultima tertutup apabila diikuti konsonan bilabial dan palatal.

Formula korespondensi fonemis /a o/, fonem proto *a dalam bahasa Aceh tetap dipertahankan fonem /a/, sedangkan fonem proto *au dalam bahasa Gayo direfleksikan menjadi /o/. Korespondensi fonemis /a o/ pada bahasa Aceh dan bahasa Gayo muncul pada posisi penultima terbuka dan penultima tertutup yang diikuti konsonan palatal, dorsovelar, dan faringal.

Formula korespondensi fonemis /o u/, fonem proto $* \mathrm{u}$ dalam bahasa Aceh direfleksikan menjadi fonem /o/, sedangkan fonem proto *u dalam bahasa Gayo tetapdipertahankan dalam /u/. Korespondensi fonemis /o u/ pada bahasa Aceh dan bahasa Gayo muncul pada posisi penultima tertutup apabila diikuti konsonan bilabial, dorsovelar, palatal, faringal.

Formula korespondensi fonemis /e u/, fonem proto *u dalam bahasa Aceh direfleksikan menjadi fonem /e/, sedangkan proto fonem *u dalam fonem bahasa Gayo tetap dipertahankan /u/. Formula korespondensi fonemis /e u/ muncul pada posisi penultima tertutup diikuti dorsovelar.

\section{Simpulan}

Berdasarkan analisis yang telah diuraikan, maka dapat ditarik simpulan bahwa antara bahasa Aceh dan Gayo memperlihatkan bentuk korespondensi fonemis yang teratur dalam bentuk vokal. Formula korespondensi fonemis dalam bahasa Aceh dan bahasa Gayo yang didapat adalah:

$*_{\mathrm{a}}>\mathrm{BA}=\mathrm{a}$

$\mathrm{BG}=\mathrm{e}, \mathrm{o} \quad$ Penultima $\mathrm{C}$ : bilabial, palatal, dorsovelar, faringal

$* \mathrm{u}>\mathrm{BA}=\mathrm{o}, \mathrm{e}$

$\mathrm{BG}=\mathrm{u} \quad$ Penultima $\mathrm{C}$ : bilabial, dorsovelar, palatal, faringal. 


\section{Daftar Pustaka}

Bakar, Aboe, dkk. 1985. Kamus Aceh-Indonesia. Jakarta: Pusat Pembinaan dan Pengembangan Bahasa Departemen Pendidikan dan Kebudayaan.

Keraf, Gorys. 1996. Linguistik Bandingan Historis. Jakarta: Gramedia Pustaka Utama.

Melalatoa, M.J, dkk. 1985. Kamus Gayo-Indonesia. Jakarta: Pusat Pembinaan dan Pengembangan Bahasa Departemen Pendidikan dan Kebudayaan.

Tiani, Riris. "Korespondensi Fonemis Bahasa Bali dan Bahasa Sumbawa" jurnal KAJIAN SASTRA. Vol.34 no 2 Juli 2010.

Wurm, S.,A., \& B. Wilson. 1978. English finderlist of Reconstructions InAustronesian Languages (Post-Brandstetter). Australia: Department of Linguistics Research School of Pasific Studies. 